\title{
A STUDY ON CHANGES IN THICKNESS OF STS304 MATERIAL IN THE PROGRESSIVE DRAWING PROCESS
}

In the drawing process, the roundness of corners in the punch and the die are very important factors in determining the thicknesses of the product. The results clearly revealed that the thickness of a flange was increased and the thickness of body parts reduced when the roundness of the die entrance was small. The material thickness of the top part was decreased when the corner roundness of the punch was large. The smooth inflow of materials was found to have a significant effect on the thickness during the post-process. The compressive strength of STS 304 material exhibited a higher value compared with other processing methods. Moreover, we clearly observed the corner roundness of the punch and the die to be a very important factor for STS 304 materials.

Keywords: Body thickness, Drawing; Flange thickness, Corner roundness, Material thickness

\section{Introduction}

Stainless steels are utilized in various fields; however the applications of steel are relatively limited due to low strength and low durability. For broader applications, it is necessary to increase the strength of materials through grain refinement using different methods [1]. Different kinds of processes can create different structures, including refinement, volume fraction of grain boundaries, and density of dislocations, all of which influences the thickness, composition, and corrosion resistance [2]. The drawing process is an effective method, where hollow containers without a seam are produced after the material for a flat plate is flown into a die using a punch. To flow the flat plate material into die without produing cracks or wrinkles, pressure of the blank holder, drawing speed, roundness at entrance corners of the punch and the die are very crucial parameters for STS 304 materials.

In a study on the effects of the Die PAD method on concentricity and side wall thickness of products in multi-stage drawing processing [3] together with a study on the effects of independent type and independent structure of the die pad on the product thickness. Lee [4], showed that the product thickness was increased by using the independent type of pad for the 1st through the 6th processes and a mixed type of integrated type for the 7th and the 8th processes. it also showed that the use of appropriate ironing process in the process of an intermediate stage made maintenance of concentricity easier.

Through the study on thickness deformation of material of a circular forming shape for PCB mounting. Lee [5], found that the die entrance corner should be provided with a roundness of about
$50 \%$ of the product height in the 1 st forming as the 1 st forming shape had an effect on the material thickess in the 2nd forming.

Through the study on the structure design of the punch and the die plate for restriking dies, Kim [6], has presented a shape design for the punch and the die block capable of drawing forming and restriking using 1 set of dies. Kim et al. [7] conducted a study on thickening methods only for desired wall parts after producing an intermediate shape by deep drawing included in a new sheet-bulk forming method through the design of die and the process for wall thicknesses upon forming of quadrangle plate materials, through which minimization of material waste and manufacturing time was stated to be possible. In the present study, drawing processes are to be sequentially implemented by using progressive dies, and changes in product thickness as a function of changes in corner roundness of the die and the punch are studied in each process.

\section{Experimental procedure}

\subsection{Preparation of progressive drawing dies}

\subsubsection{Analysis of material and design of drawing products}

For the processed plate material used in this experiment, 3.0 mm-thick STS 304 was selected by considering ease of measurement for material thicknesses and capacity of the press. The thickness of the material prior to the experiment was measured to be $2.98 \mathrm{~mm}$.

\footnotetext{
* DEPARTMENT OF METAL DIE DESIGN ENGINEERING, YUHAN UNIVERSITY

** DIVISION OF MECHANICAL \& AUTOMOTIVE ENGINEERING, KONGJU NATIONAL UNIVERSITY, CHEONAN-SI, REPUBLIC OF KOREA 
To consider the microstructures of the material, test specimens were collected in a longitudinal direction and mounted in synthtic resin (thermosetting resin). Also, following manual polishing, they were subjected to corrosion processing using an aqueous solution with a mixture of $5 \mathrm{~cm}^{3}$ of concentrated nitric acid solution and $100 \mathrm{~cm}^{3}$ of alcohol. According to the analysis results of the microstructure, the base metal was found to consist of austenite and a small amount of ferrite due to Ni being the austenite-stabilizing element. Shown in Fig. 1 are pictures of test specimens and microstructures.

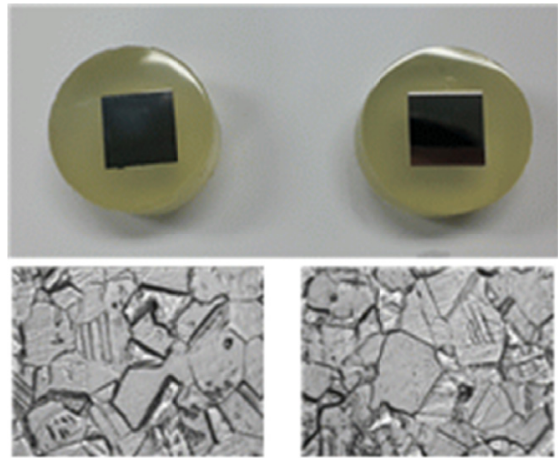

Fig. 1. Example for specimen and microstructure of strip

For mechanical testing, tensile test specimens for plate material (KS No. 5) were prepared, and tensile tests were conducted as shown in Fig. 2, with the result values shown in Fig. 3 and Table 1.
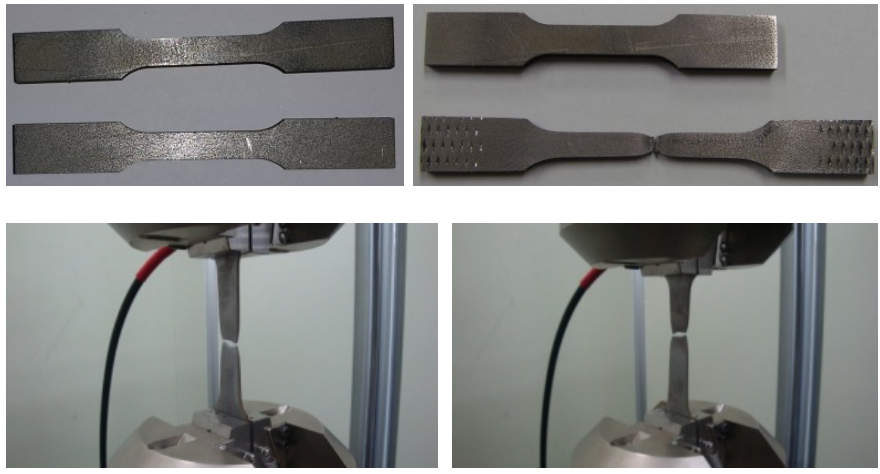

Fig. 2. Specimen tensile test

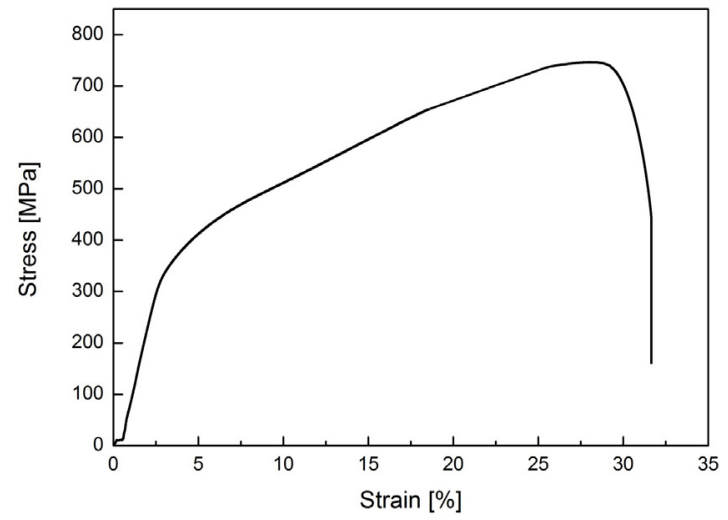

Fig. 3. Stress-strain curve measured for STS 304 material
TABLE 1

Mechanical test results

\begin{tabular}{|c|c|c|}
\hline \hline Classification & Tensile Strength & Yield Strength \\
\hline Minimum standards & $\geqq 520 \mathrm{MPa}$ & $\geqq 216 \mathrm{MPa}$ \\
\hline Test material & $746 \mathrm{MPa}$ & $340 \mathrm{MPa}$ \\
\hline
\end{tabular}

The material used in the experiments was STS 304, and this could be seen to be a material with somewhat strong mechanical properties as the tensile strength was shown to be $746 \mathrm{MPa}$, and the yield strength was $340 \mathrm{MPa}$ according to the result of comparison with the minimum standard.

The product used in the present experiment was housing for fuel injection apparatus as one of the automotive components. Although a round bar material was machined by a CNC lathe for use in the past, the thickness of the product should be increased since dimensional precision is determined by lathe machining rather than the all dimensions being satisfied as this is to be used by completion of machining with a CNC lathe after drawing processing. The product drawing used for the experiment is shown in Fig. 4.
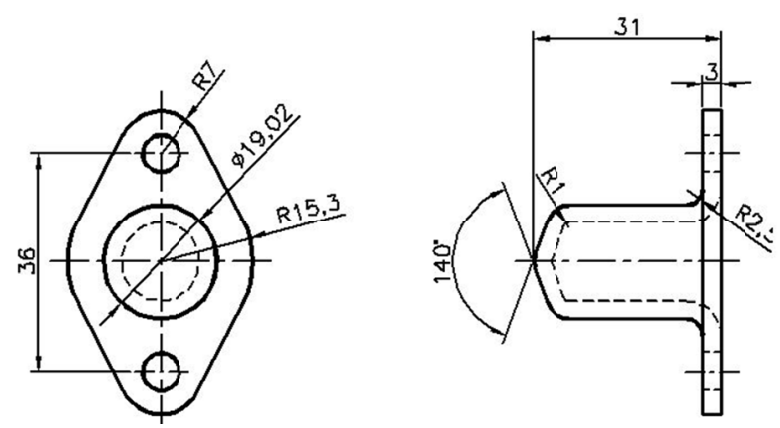

Fig. 4. Product drawing of the experiment

\subsection{Preparation of progressive drawing dies}

The dimensions of the blank were determined by considering the drawing coefficient and drawing ratio of the drawing product, each outer diameter and height of the drawing was determined to allow for stable forming of the product by progressive drawing, and the layout for the strip was prepared. As indicated in Fig. 5, the carrier for supporting the product was set to $3.0 \mathrm{~mm}$ for stable transfer of the product, while the transfer spare width was set to be $8.0 \mathrm{~mm}$ for installation of the pilot pin, and strip layout was completed by setting to $78.0 \mathrm{~mm}$ in the transfer pitch, and $70.0 \mathrm{~mm}$ in the material width.

Progressive drawing dies were prepared by referring to the designed drawing. In the 1st drawing, the force of the blank holder was set to be $28.224 \mathrm{kN}$ to suppress occurrence of wrinkles, while $8.584 \mathrm{kN}$ was set from the 2nd drawing through the 9th drawing. In addition, to prevent canning phenomenon of the product after drawing processing, an air hole was provided for smooth inflow of air into the drawing punch and the die.

Drawing punches used for each process are shown in Fig. 6, and the assembly drawing for progressive drawing dies is shown in Fig. 7. 

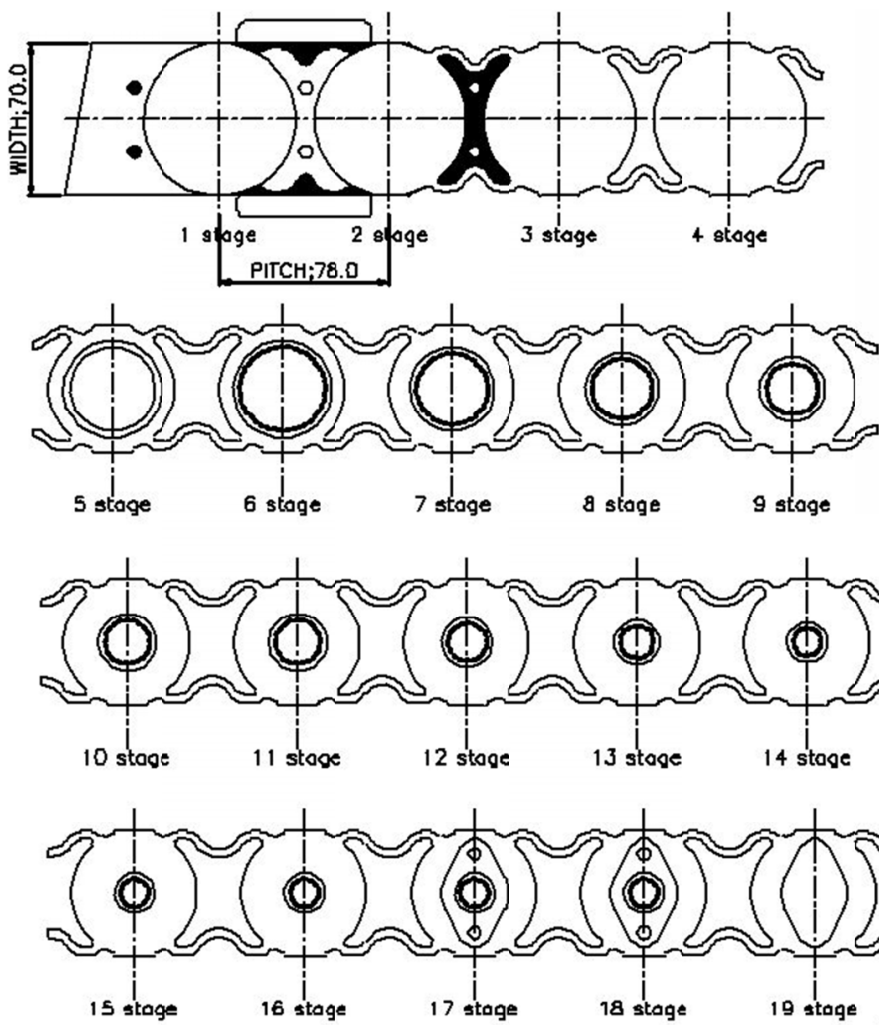

Fig. 5. Strip layout of drawing die

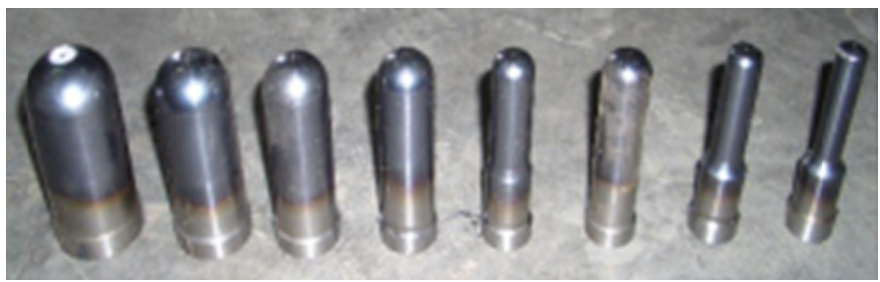

Fig. 6. Drawing punch

\section{Experimental results and discussions}

CS250-ton Double crank press was employed in the experiment, and the drawing speed was set to $16 \mathrm{~m} / \mathrm{min}$. The same conditions were applied for the force of the blank holder and lubrication. Thickness changes of the product were studied and considered while the outer diameter and the height of the drawing products were set to be the same as the roundness of the punch corners, and the die entrance corners were varied. While the die part was designated as 0101, 0201, etc. As shown in Table 2, the front two digits of the figure show the experimental sequence, and the rear two digits show the drawing process sequence.

TABLE 2

Die set system

\begin{tabular}{|c|c|c|c|c|c|}
\hline \hline \multicolumn{3}{|c|}{ 1st test } & \multicolumn{3}{c|}{ 2nd test } \\
\hline Die part & Die “R” & Punch “R” & Die part & Die “R” & Punch “R” \\
\hline 0101 & 15 & 16 & 0201 & 17 & 18 \\
\hline 0102 & 14 & 14 & 0202 & 16 & 16 \\
\hline 0103 & 13 & 12 & 0203 & 15 & 14 \\
\hline 0104 & 11 & 10 & 0204 & 13 & 12 \\
\hline 0105 & 9 & 8 & 0205 & 11 & 10 \\
\hline 0106 & 7 & 6 & 0206 & 9 & 8 \\
\hline 0107 & 5 & 4 & 0207 & 7 & 6 \\
\hline 0108 & 4 & 10 & 0208 & 4 & 10 \\
\hline 0109 & 2.5 & 1 & 0209 & 2.5 & 1 \\
\hline
\end{tabular}

The shape of the product used in the present study was designed to allow various processes to be drawn by a die. Products obtained through experiments are shown in Fig. 8, while measurement positions for the product completed in each process are shown in Fig. 9, with the data obtained from each experiment given in (b) and (a) of Table 3. Also, the products obtained through the experiment are shown in Fig. 10.
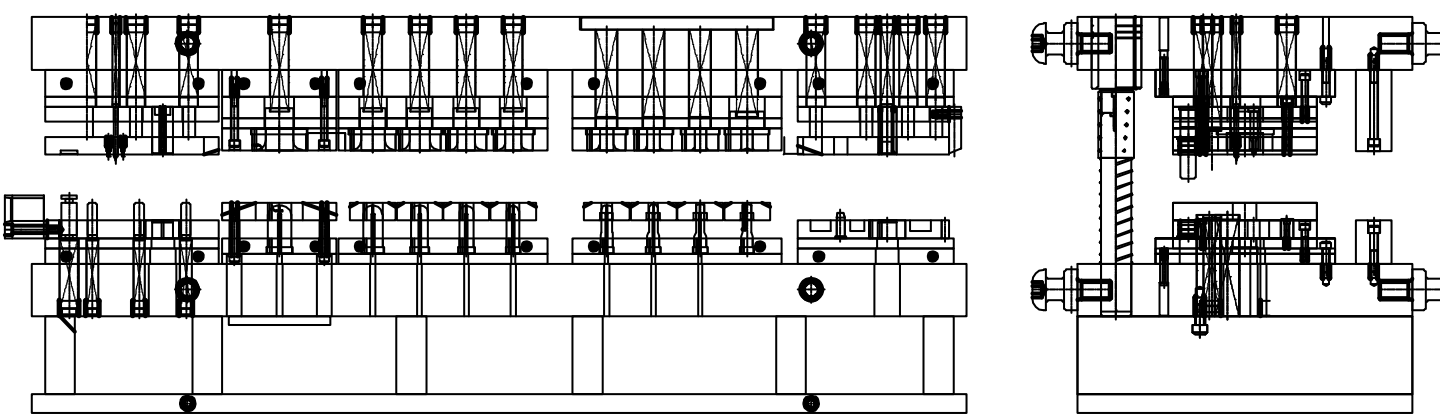

Fig. 7. Progressive drawing die-set

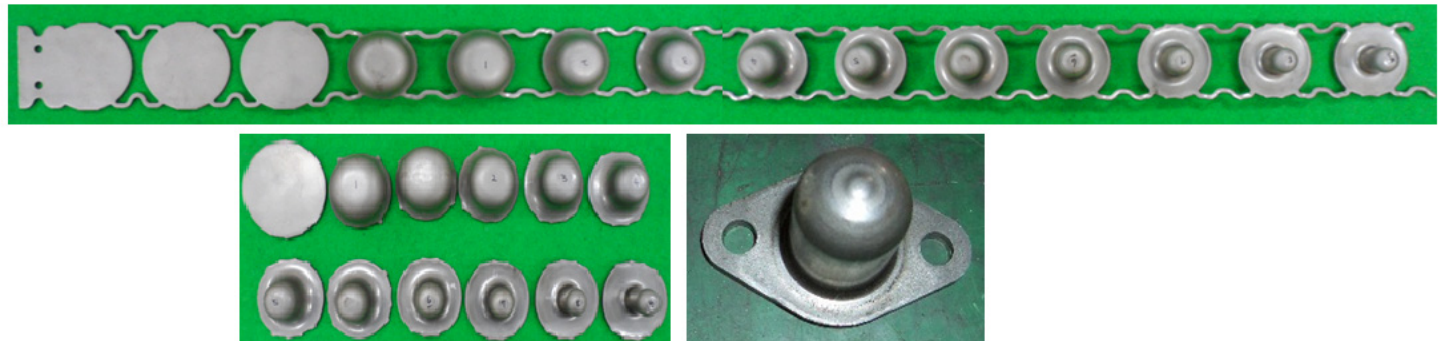

Fig. 8. Strip and Product 


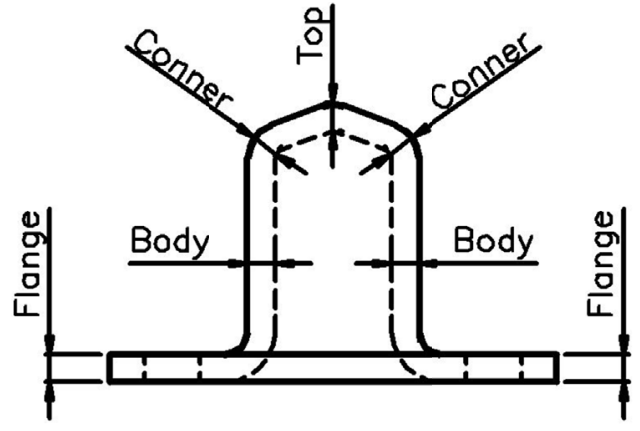

Fig. 9. Measuring points
Three samples of the product processed in the experiment using progressive drawing dies were prepared, and Flange, Body, Corner Roundness, and Top were measured using a noncontacttype optical microscope (magnifications of 30X 210X) for comparisons between the results obtained from the 1st and 2nd experiments.

As shown in Fig. 11, the material thickness of $2.98 \mathrm{~mm}$ was increased to a maximum of $3.238 \mathrm{~mm}$ for the flange part, and much reduced to a minimum of $1.542 \mathrm{~mm}$ for the corner roundness formed by the punch when the corner roundness of die entrance was made to be small, according to the 1st experi-

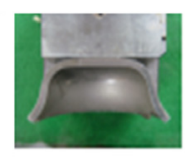

0101

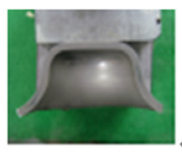

0102

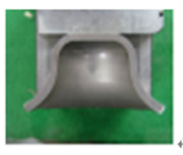

0103

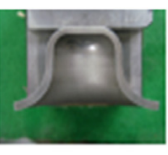

0104

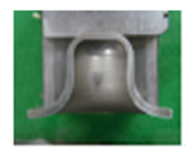

0105

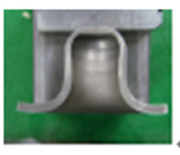

0106

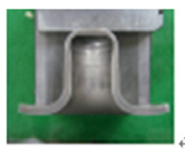

0107

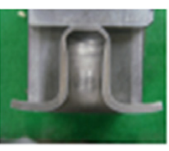

0108

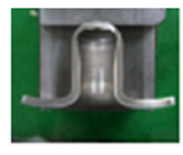

0109

(a) 1 st experiment

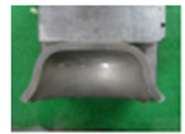

0201

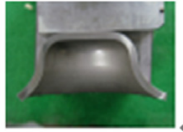

0202

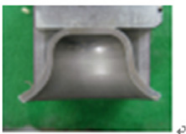

0203

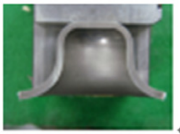

0204

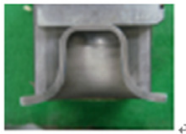

0205

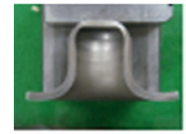

0206

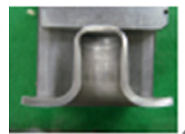

0207

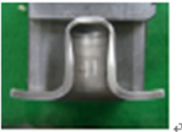

0208

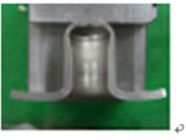

0209

(b) 2nd experiment

Fig. 10. Product test results

TABLE 3

Measurement results

(a) 1 st test

\begin{tabular}{c|c|c|c|c|c}
\hline \multirow{2}{*}{$\begin{array}{c}\text { Die } \\
\text { part }\end{array}$} & \multicolumn{4}{|c|}{ Product Thickness } & \multirow{2}{*}{ Process name } \\
\cline { 2 - 5 } & Flange & Body & Corner & Top & \\
\hline 0101 & 3.161 & 2.879 & 2.587 & 2.828 & 1st Drawing \\
\hline 0102 & 3.170 & 2.853 & 2.570 & 2.791 & 2th Drawing \\
\hline 0103 & 3.238 & 2.641 & 2.439 & 2.637 & 3th Drawing \\
\hline 0104 & 3.165 & 2.648 & 2.342 & 2.431 & 4th Drawing \\
\hline 0105 & 3.160 & 2.551 & 2.061 & 2.344 & 5th Drawing \\
\hline 0106 & 3.123 & 2.866 & 1.802 & 2.319 & 6th Drawing \\
\hline 0107 & 3.116 & 2.949 & 1.542 & 2.314 & 7th Drawing \\
\hline 0108 & 3.112 & 3.041 & 1.666 & 2.323 & 1st Restriking \\
\hline 0109 & 3.096 & 2.960 & 1.646 & 2.364 & 2th Restriking \\
\hline
\end{tabular}

ment results. The thinning phenomenon is considered to occur as a result of obstructed inflow of the material. Also, the thickness of corner part was formed to be thin in the 7th drawing process, while it was shown to be slightly increased again by the restriking process in the 8th and the 9th drawing processes.

Based on the results obtained from the first experiments, experiments were conducted by setting the corner roundnesses of the punch and the die to be large for smooth inflow of the material and securing the thickness dimension for the product. At this time, the same conditions as those for the first experiments were also applied for the force of the blank holder, drawing (b) Second Test

\begin{tabular}{c|c|c|c|c|c}
\hline \multirow{2}{*}{$\begin{array}{c}\text { Die } \\
\text { part }\end{array}$} & \multicolumn{4}{|c|}{ Product Thickness } & \multirow{2}{*}{ Process rame } \\
\cline { 2 - 5 } & Flange & Body & Corner & Top & \\
\hline 0201 & 3.070 & 2.887 & 2.620 & 2.817 & 1st Drawing \\
\hline 0202 & 3.051 & 3.038 & 2.595 & 2.784 & 2th Drawing \\
\hline 0203 & 3.206 & 3.078 & 2.446 & 2.626 & 3th Drawing \\
\hline 0204 & 3.079 & 2.664 & 2.350 & 2.416 & 4th Drawing \\
\hline 0205 & 3.098 & 2.653 & 2.080 & 2.328 & 5th Drawing \\
\hline 0203 & 3.045 & 2.887 & 1.897 & 2.294 & 6th Drawing \\
\hline 0207 & 3.010 & 2.986 & 1.586 & 2.301 & 7th Drawing \\
\hline 0203 & 3.005 & 3.064 & 1.683 & 2.308 & 1st Restriking \\
\hline 0209 & 2.980 & 3.016 & 1.656 & 2.343 & 2th Restriking \\
\hline
\end{tabular}

speed, and lubrication.

According to the experimental results, the flange thickness was shown to be $3.206 \mathrm{~mm}$, which was slightly thinner than the dimension obtained from the first experiment, while the corner formed by the punch corner showed a slightly large thickness of $1.586 \mathrm{~mm}$.

In the 7th drawing process, the corner was formed to have a very small thickness as in the first experiments, and the thickness was shown to be increased again by the restriking process in the 8th and 9th processes. The results obtained from the second experiment are shown in Fig. 12. 


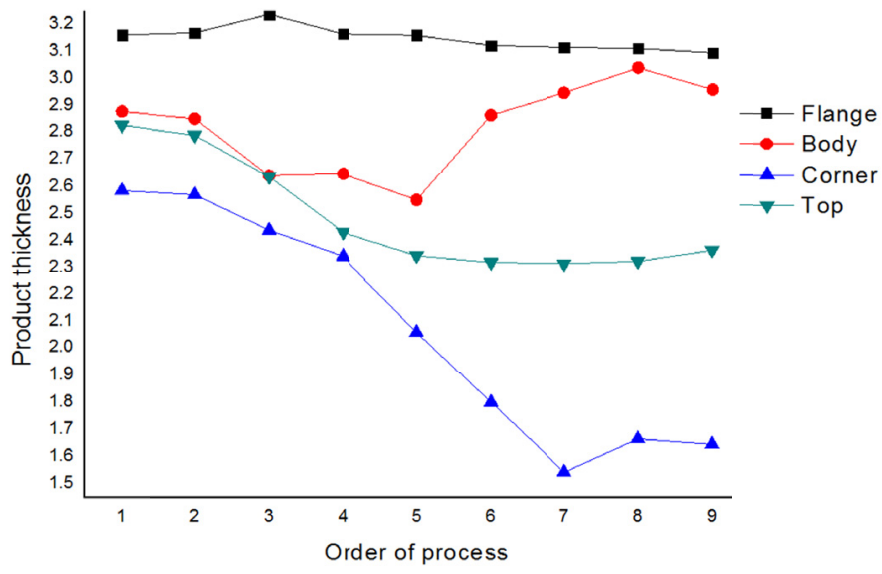

Fig. 11. Experimental results for small edge cases

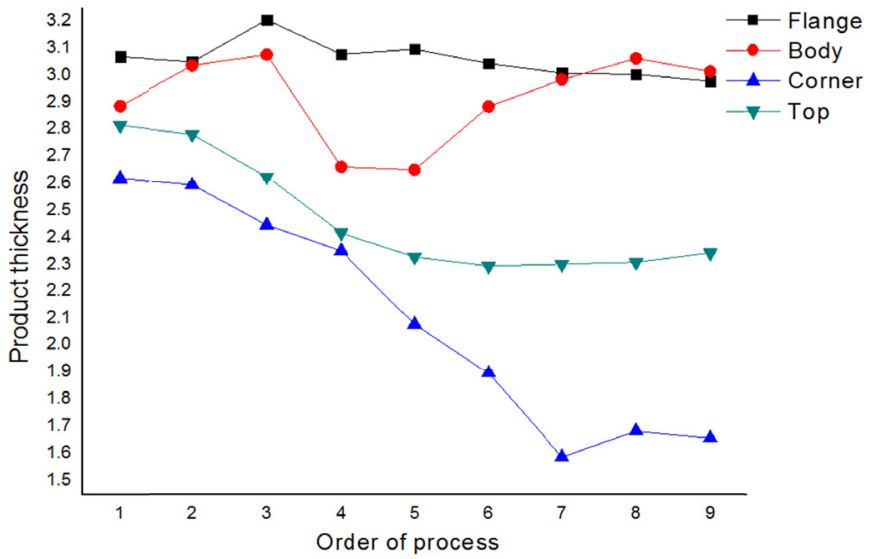

Fig. 12. Experimental results of large edge cases

According to the first experiment results where corner roundnesses of the punch and the die were made to be small and the second experiment results where the corner roundness was set to be large, it could be seen that inflow of the material varied depending on the magnitude of corner roundness, by which the product thickness was affected.

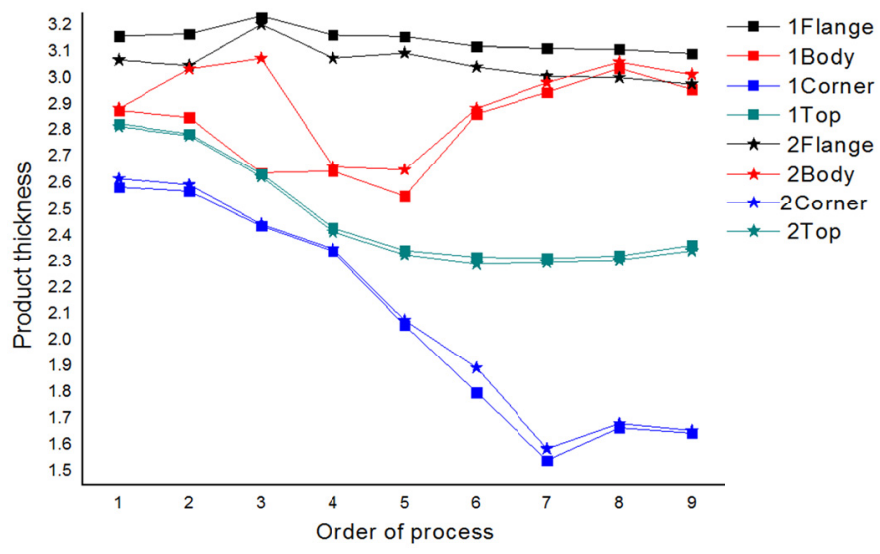

Fig. 13. Comparison of two experimental results
In the first experiments where the flange thickness was too large, the thickness was almost unchanged even when drawing processes were sequentially implemented. In the second experiments, the flange thickness was slightly reduced with an increase in the corner roundness of the die, and the thickness could be seen to be gradually reduced as a result of sequential execution of drawing. This is considered to be the result that shutoff of material inflow by the die corner was somewhat alleviated.

What showed the largest thickness change through the experiments was the body part in the 3rd drawing, which showed a very small thickness of $2.641 \mathrm{~mm}$ in the first experiment and a thickness of $3.078 \mathrm{~mm}$ in the second experiment. This is due to the effects of the 1st drawing and the 2nd drawing. This is considered as a result attributable to the corner roundness of the die entrance.

\section{Conclusions}

Based on the above experimental results and discussion, the following conclusions may be drawn as a result of studying changes of product thickness as a function of corner roundness of the punch and the die using progressive drawing dies.

1) Product thickness was shown to be affected by the corner roundness of the punch and the die in drawing processes even under the conditions where shearing speed, lubrication condition, and pressure of the bank holder were the same.

2) When the corner roundness of the die entrance was small, the thickness of the flange part was shown to be larger than that of the material due to suppression of inflow of the material.

3) When the corner roundness of the punch was small, the effects on thickness change of the top were suppressed, causing the product thickness at the corner to be small.

4) For an increase in thickness of the body part and corner part, the corner roundness of the punch and the die could be seen to be a very important factor.

\section{REFERENCES}

[1] Z.J. Zheng, Y. Gao, Y. Gui, M. Zhu, Corrosion Science 54, 60 (2012).

[2] L. Liu, Y. Li, F.H. Wang, J. Mater. Sci. Technol. 26, 1 (2010).

[3] C.K. Lee, J. Korean Soc. Mech. Technol. 17, 1285 (2015).

[4] C.K. Lee, J. Korea Saf. Manag. Sci. 15, 2 (2013).

[5] C.K. Lee, Journal of the Korea Academia-Industrial cooperation Society, pp 3667-3671 (2015).

[6] S.H. Kim, Journal of the Korea Academia-Industrial cooperation Society 8, 708 (2007).

[7] J.H. Kim, S.M. Hong, Journal of the Korea Academia-Industrial cooperation Society 16, 5789 (2015). 